\title{
A preliminary fault model of the 2003 July 26, M6.4 northern Miyagi earthquake, northeastern Japan, estimated from joint inversion of GPS, leveling, and InSAR data
}

\author{
Takuya Nishimura ${ }^{1}$, Tetsuro Imakiire ${ }^{1}$, Hiroshi Yarai ${ }^{1}$, Taku Ozawa $^{2}$, Makoto Murakami $^{1}$, and Masaru Kaidzu $^{1}$ \\ ${ }^{1}$ Geographical Survey Institute, Geography and Crustal Dynamics Research Center, Kitasato-1, Tsukuba, Ibaraki 305-0811, Japan \\ ${ }^{2}$ Japan Society for the Promotion of Science/ Geographical Survey Institute, Kitasato-1, Tsukuba, Ibaraki 305-0811, Japan
}

(Received September 30, 2003; Revised December 25, 2003; Accepted December 26, 2003)

\begin{abstract}
A shallow M6.4 earthquake with a M5.6 foreshock and the M5.5 largest aftershock occurred in northern Miyagi Prefecture, northeastern Japan on July 26, 2003. The coseismic displacement was observed not only by GEONET (continuous GPS) but also by campaign GPS, leveling, and InSAR. We have plenty of displacement data by multiple geodetic measurements, which is unusually abundant as the M6-class earthquakes. The leveling route in the epicentral area was surveyed on the day just before the earthquake by chance, and that it was resurveyed just after the earthquake. RADARSAT SAR interferograms provide high resolution of surface displacements which reach $240 \mathrm{~mm}$. We construct coseismic rectangular fault model by inversion of the multiple geodetic data. The number of observation points used in the inversion are 23, 17, 49 and 1601 for continuous GPS, campaign GPS, leveling, and InSAR, respectively. We found that two thrust-type fault segments whose strike differs by $50^{\circ}$ were necessary to reproduce the observed deformation. Seismic moment for both segments is $1.8 \times 10^{18} \mathrm{~N} \cdot \mathrm{m}\left(\mathrm{M}_{w} 6.1\right)$, assuming rigidity of $30 \mathrm{GPa}$. Because rake angle of two segments is different by only $15^{\circ}$, azimuth of slip vectors is significantly different between two faults. Two segments having different orientation can explain the apparent disagreement of focal mechanisms estimated from initial phase of $\mathrm{P}$ wave and CMT waveform inversion.
\end{abstract}

Key words: Crustal deformation, northeastern Japan, earthquake, GPS, leveling, InSAR.

\section{Introduction}

The northeastern Japan arc is an island arc beneath which the Pacific plate is subducting with a rate of about $8 \mathrm{~cm} / \mathrm{yr}$. Japanese nationwide GPS network (GEONET) maintained by the Geographical Survey Institute (GSI) shows contemporary east-west compression of the island arc (Sagiya et al., 2000), which is attributed to strong coupling between the subducting Pacific plate and the overriding continental plate (e.g. Nishimura et al., 2004b). Miyagi Prefecture (Fig. 1) locates on the Pacific side of the northeastern Japan arc and has large strain rate observed by GEONET (Sagiya et al., 2000). M 7.5 earthquakes including the M7.4 1978 Miyagi-Oki earthquake have occurred roughly every 40 years on the subducting plate boundary east of Miyagi Prefecture, where plate interface almost completely locked during 1995-2002 (Nishimura et al., 2004b). The Headquarters for Earthquake Research Promotion of the Japanese government estimated the probability of a M 7.5 earthquake within the next 30 years to be $98 \%$ (report is available at http://www.jishin.go.jp/main/index-e.html in Japanese).

The shallow inland earthquakes occurred on July 26, 2003 in northern Miyagi Prefecture. The earthquake sequence started from a foreshock with a magnitude of 5.6 at AM 00:13 of the local (Japan Standard) time that day. The M6.4 main-shock occurred at AM 7:13 and the M5.5 largest after- shock followed at PM 4:56 of the same day (Fig. 1). Maximum acceleration of the ground shaking of the repeating earthquakes, collected by the Japan Meteorological Agency was larger than gravitational one at some local stations for seismic intensity. The strong shaking made hundreds of people injured and caused severe damage of buildings in the epicentral region. Because the epicenters of these earthquakes are covered by GEONET, coseismic displacement of the earthquake was clearly observed. The M7.1 MiyagiOki earthquake occurred on May 26, 2003, just two months before the M6.4 northern Miyagi earthquake (Fig. 1). This high-angle reverse-type earthquake occurred in the subducting Pacific slab caused a few $\mathrm{cm}$ of displacements at the GEONET stations. It motivated GSI to carry out leveling and campaign-type GPS measurements in Miyagi Prefecture. The coincidence of the M7.1 and M6.4 earthquakes in and around Miyagi Prefecture enabled us to clarify the detailed coseismic deformation of the M6.4 earthquake by lots of geodetic data.

In this study, we collect the geodetic data measured by GSI to reveal the coseismic deformation of the M6.4 earthquake. Then we estimate a fault model to fit the coseismic displacement data from ground-based measurements (GPS and leveling) as well as remote sensing data from a satellite (InSAR). 


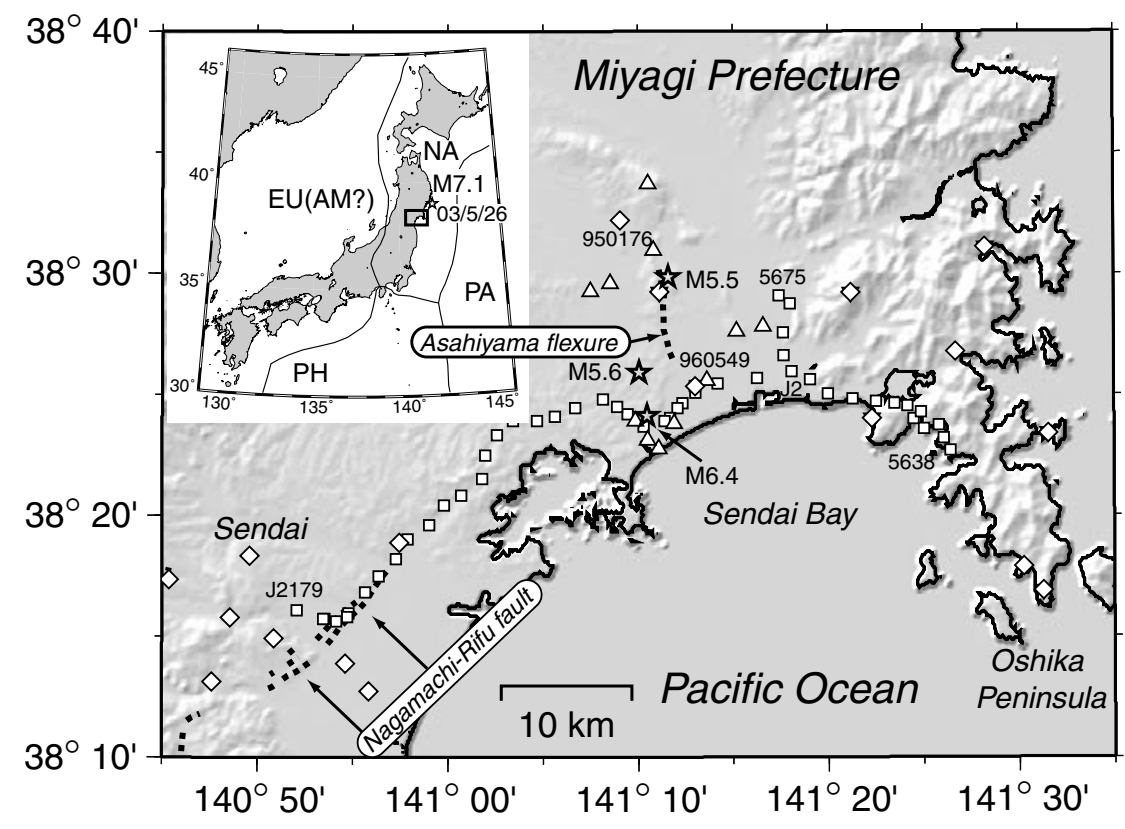

Fig. 1. Shaded-relief topographic map showing geodetic stations and epicenters of earthquakes. The stars with M6.4, M5.6 and M5.5 indicate epicenters of the main-shock, the largest foreshock, and the largest aftershock on July 26, 2003, respectively. The thick dotted lines indicate surface traces of the Quaternary faults (Active Fault Research Group, 1991). Open squares, diamonds, triangles, and vertical triangles indicate locations of leveling benchmarks, continuous GPS stations, triangulation benchmarks, and monuments for a campaign GPS used in this study, respectively. Six digit numbers indicate the name of the selected continuous GPS stations. Abbreviation in tectonic map (inset) is NA, PA, PH, EU and AM for North America, Pacific, Philippine Sea, Eurasia, and Amurian plates, respectively.

\section{Data}

\subsection{GPS}

We took coseismic displacement data from three types of GPS measurements. First type of the measurements is continuous GPS. We used data acquired from GEONET and the other continuous GPS systems in Miyagi Prefecture (Nishimura et al., 2004a). All used GPS stations are maintained by GSI. The total number of the continuous GPS stations is 23 . We regarded the difference between average coordinates from July 17 to 25 and those from July 27 to August 5 as the coseismic displacement plotted in Figs. 2 and 3. The plotted displacement is relative to site 970797 which locates $60 \mathrm{~km}$ southwest of the epicenter in Shiroishi City of Miyagi Prefecture. The maximum displacement observed at 960549 in Yamoto Town amounts to $\sim 160 \mathrm{~mm}$ southeast for horizontal component and $\sim 90 \mathrm{~mm}$ uplift for vertical component. The tiltmeter equipped in the GPS pillar of 960549 recorded $\sim 0.1$ degree tilt change of the pillar at the occurrence of the earthquake. If the base of the monument was fixed, it corresponds to $\sim 10 \mathrm{~mm}$ of horizontal displacement at the top of the pillar where a GPS antenna is set. Horizontal displacement at the top was also measured to be 10 $\mathrm{mm}$ with transit by a survey technician of GSI. Though it suggests instability of the GEONET monument caused by strong ground motion, the effect of the monument instability can be negligible because the displacement calculated from the tilt change is much smaller than the observed one. There are no other GEONET stations which tilted at the time of the earthquake.

Second and third types of GPS measurements are both campaign GPS. We divided them into two types because their method and expected errors are quite different. Sec- ond type of the measurement aims to observe crustal deformation in and around Oshika Peninsula. There are six stations of permanent monuments consisting of a concrete base and a $3 \mathrm{~m}$ tall pillar on the east side of the epicentral region. Because there is an anchored bolt on the top of the pillar, we can eliminate errors of centering the GPS antenna on benchmarks. The pre-seismic measurement was accomplished in July 1 and 2, 2003. The GPS data acquired for more than 15 hours on each day. These stations were measured for more than 48 hours from August 5 with GPS again. We found large coseismic displacement, which is $155 \mathrm{~mm}$ of horizontal component and $170 \mathrm{~mm}$ of vertical component in the northern part of the epicentral region. The horizontal displacement measured by first and second type is shown in Fig. 2. The triangulation points used in third type of measurements are stone benchmarks maintained by GSI and have official coordinates published by GSI as a control point for all surveying in Japan. We used the preseismic official coordinates estimated from GPS measurement which was independently conducted from 1996 to 2003 at 11 triangulation points. Though dual-frequency receivers were used in first and second type of GPS measurements, single-frequency GPS receivers were used in some preseismic surveys of third type. The postseismic surveys for these triangulation points were conducted from August 5 to 7 . Though observation time for GPS measurements differs depending on an order of triangulation points, it ranges 2 to 12 hours.

GPS baseline analyses were processed for each type of GPS measurements separately. Because the GEONET stations were included in the baseline analyses of second and third types of GPS measurements, we combined the coordinates for all GPS stations of three kinds of measurements. 


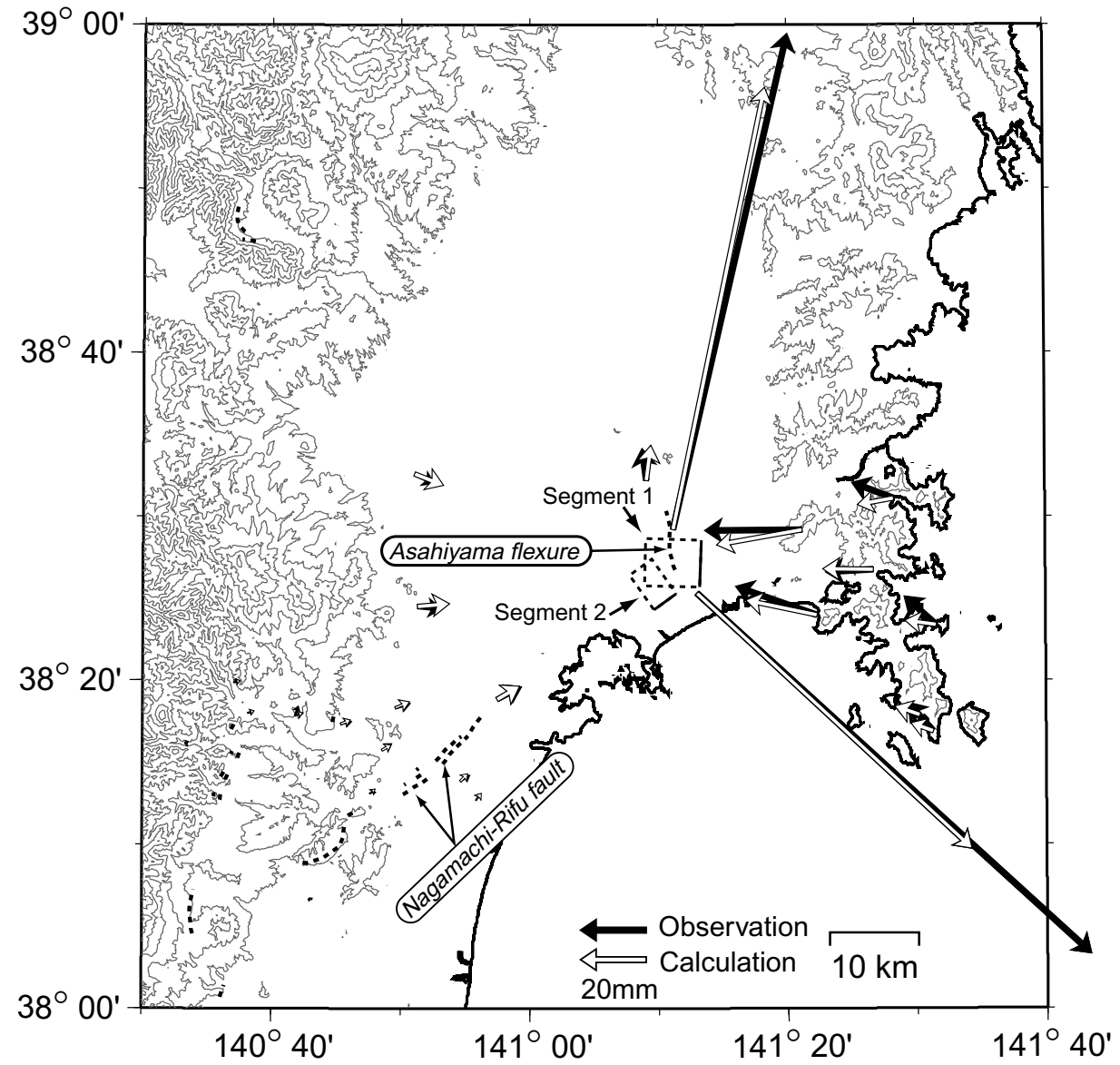

Fig. 2. Observed and calculated displacements for continuous and campaign GPS stations made from permanent monuments. The dotted rectangles show the location of the modeled faults. The solid lines on the rectangles show their upper edges.

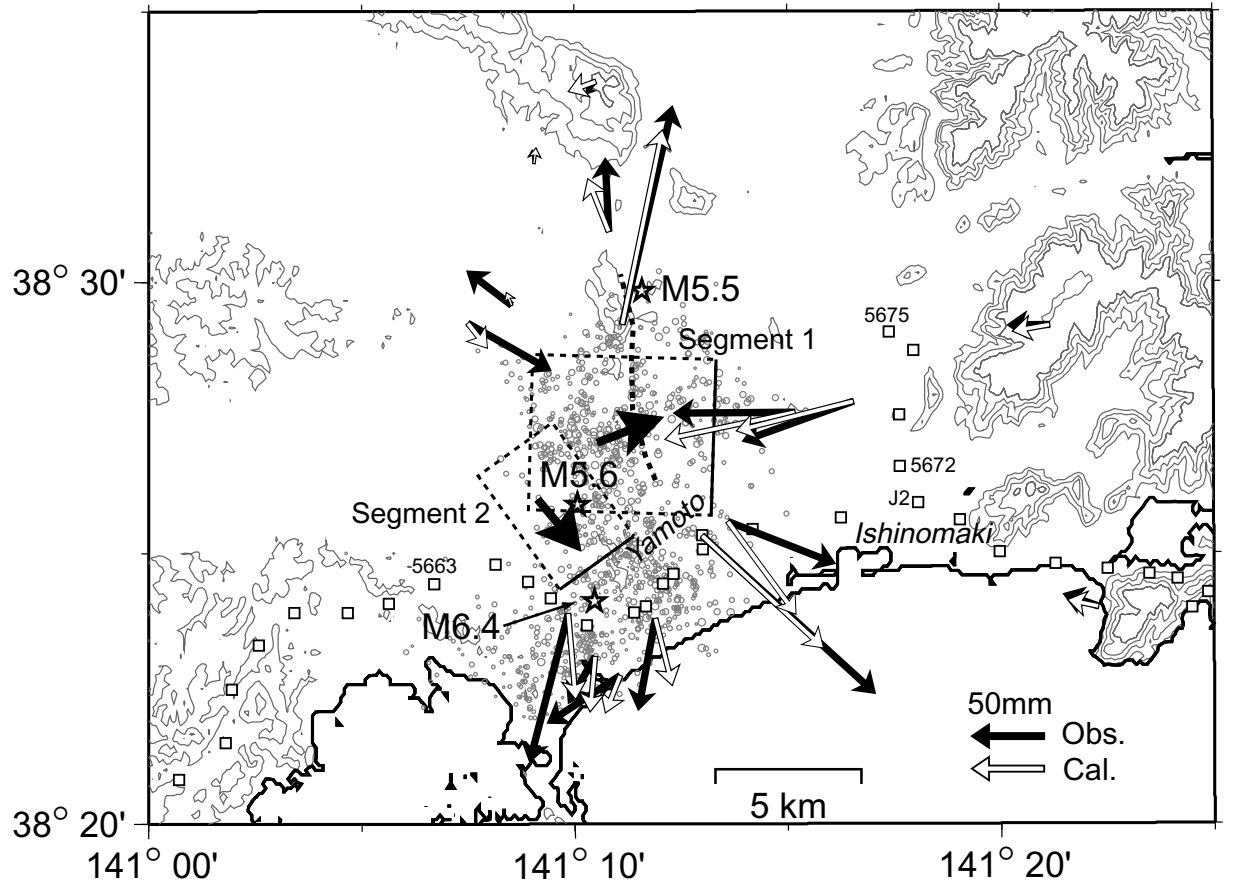

Fig. 3. Observed and calculated displacements at all stations measured by GPS in the vicinity of the epicenters. The stars with M6.4, M5.6 and M5.5 indicate epicenters of the main-shock, the largest foreshock, and the largest aftershock on July 26, 2003, respectively. Open squares indicate leveling benchmarks. The dotted rectangles show the location of the modeled faults. The solid lines on the rectangles show their upper edges. Thick black allows on the modeled faults denote the horizontal projections of the slip vectors which indicate the motion of the hanging wall side with respect to the footwall side. 


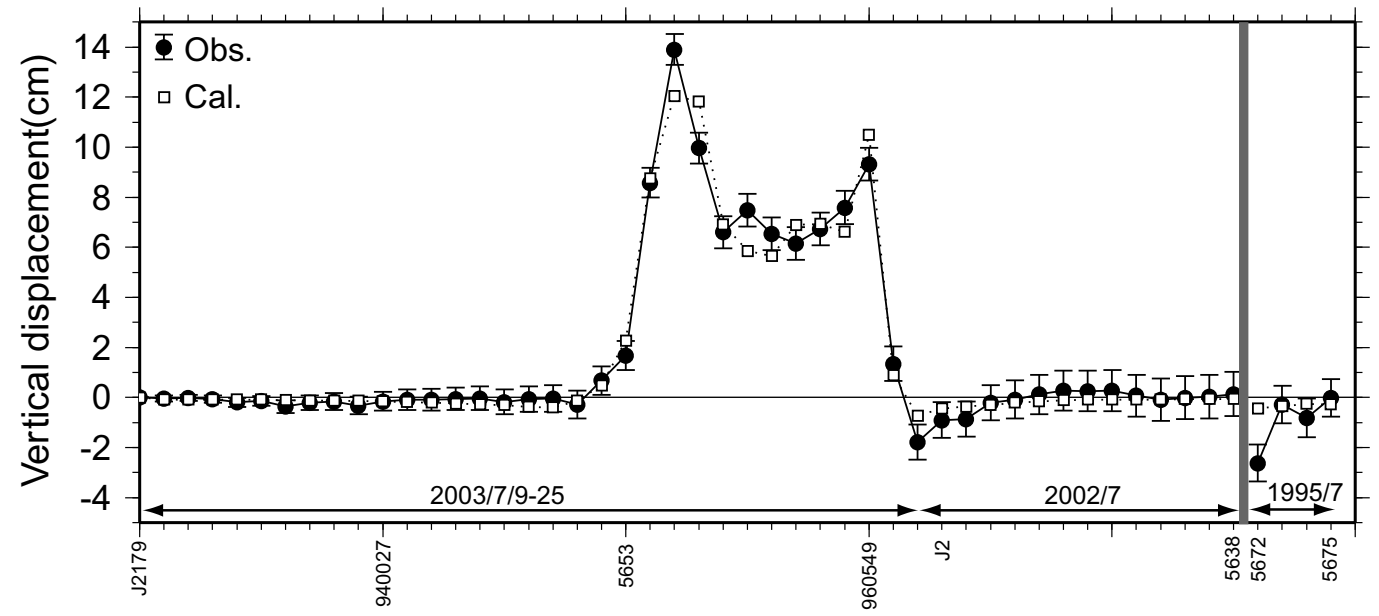

Fig. 4. Vertical displacement measured by leveling. Solid circles with error bars and open squares indicated observation and calculation, respectively. A leveling route starts at $\mathrm{J} 2179$ and branches at $\mathrm{J} 2$. It terminates at 5638 and 5675 . Year and month of the preseismic leveling are indicated in the bottom of the figure.

In Figs. 2 and 3, we plotted horizontal displacement with respect to 970797 for all GPS stations.

\subsection{Leveling}

A leveling route crosses the epicentral region as shown in Figs. 1 and 3. The leveling route goes from J2179 in Sendai to the tip of Oshika Peninsula. It branches at $\mathrm{J} 2$ in Ishinomaki to the north. It is noted that the leveling party started toward east in Sendai on July 9, 2003 and that it surveyed in the sections of the epicentral area on the day just before the earthquake. The leveling party started re-surveying to return along the route on the day of the earthquake. The preseismic leveling in the eastern part of the route between Sendai and Oshika Peninsula was accomplished in July 2002. The last survey in the sections from $\mathrm{J} 2$ to 5675 was conducted in July 1995. The survey date of the preseismic leveling is indicated in Fig. 4. All leveling is conducted by GSI with the first order of standards. First-order leveling is double run and its tolerance limit of difference between forward and backward measurements in a section is $2.5 \sqrt{L}$ in millimeters, where $L$ is the length of the section in kilometers.

The largest displacement reached $140 \mathrm{~mm}$ of uplift. Leveling was conducted at benchmarks on the base of continuous GPS stations, 940027 and 960549 . Uplift of $93 \mathrm{~mm}$ measured by leveling at 960549 is in good agreement with uplift of $\sim 90 \mathrm{~mm}$ measured by continuous GPS. The coincidence of the leveling survey and the earthquake reminded us that an anomalous tilt change was observed by leveling just before the 1944 M7.9 Tonankai earthquake (Sato, 1977; Sagiya, 1998). However, no clear precursor of the northern Miyagi earthquake has been yet identified in leveling data.

\subsection{InSAR}

We used SAR data acquired by the Canadian satellite, RADARSAT before and after the earthquake. RADARSAT has C-Band SAR whose wavelength is $57 \mathrm{~mm}$. The interferogram was formed by differencing the two radar images acquired from descending orbit on June 13 and July 31. We used the digital elevation model of $50 \mathrm{~m}$ grid produced by GSI to remove topographic fringes by two pass approach (Massonnet et al., 1993). We applied adaptive filter (Goldstein and Werner, 1998) to reduce noise in the interferogram.
The interferogram shows crustal deformation map in which each fringe represents the displacement of $28.5 \mathrm{~mm}$ in the line of sight (LOS) to the satellite. The used images were taken with the radar incident angle of $\sim 43^{\circ}$ from horizontal. The LOS measurements are sensitive to both east and vertical ground displacements almost equally.

Because a correlation between pre- and post-earthquake C-band radar images is bad in rice fields and hills covered by vegetation, we were able to get good coherence in a limited area of the radar image. The interferogram shows a displacement field in and around the populated area such as Ishinomaki City and Yamoto Town (Fig. 5(a)). The maximum displacement amounts to $240 \mathrm{~mm}$ of LOS in Yamoto Town. A detailed procedure to make interferograms will be presented in another paper (Yarai et al., 2003).

\section{Inversion \\ 3.1 Data weighting and reduction}

We categorized all available data into seven sub-datasets according to measurement methods and components of GPS displacement as shown in Table 1. The measurement errors of seven sub-datasets differ considerably. Though data uncertainties of some sub-datasets can be estimated from repeatability of data, we assumed the uncertainties by a trial and error approach. For continuous GPS data, we calculated standard deviation of daily relative coordinates every component and assigned it as data uncertainties. We assumed uncertainties for 960549 whose pillar tilted are five times as large as those calculated from the repeatability. The observation random error of leveling is given by $\alpha \sqrt{L}$ in millimeters, where $\alpha$ is the standard deviation calculated from several double run sections and $L$ is the length of the section in kilometers. We did not calculate actual value of $\alpha$ for the leveling used in this study but use $1.0 \mathrm{~mm} / \sqrt{\mathrm{km}}$ as $\alpha$, which is about twice of the average for all first-order leveling in Japan in 90's (M. Ohtaki, personal communication). Because there is no straightforward method to estimate observation errors for the other sub-datasets, we assumed their uncertainties arbitrarily. Uncertainties of horizontal displacements and vertical displacements at permanent pillars and horizontal dis- 
(a)
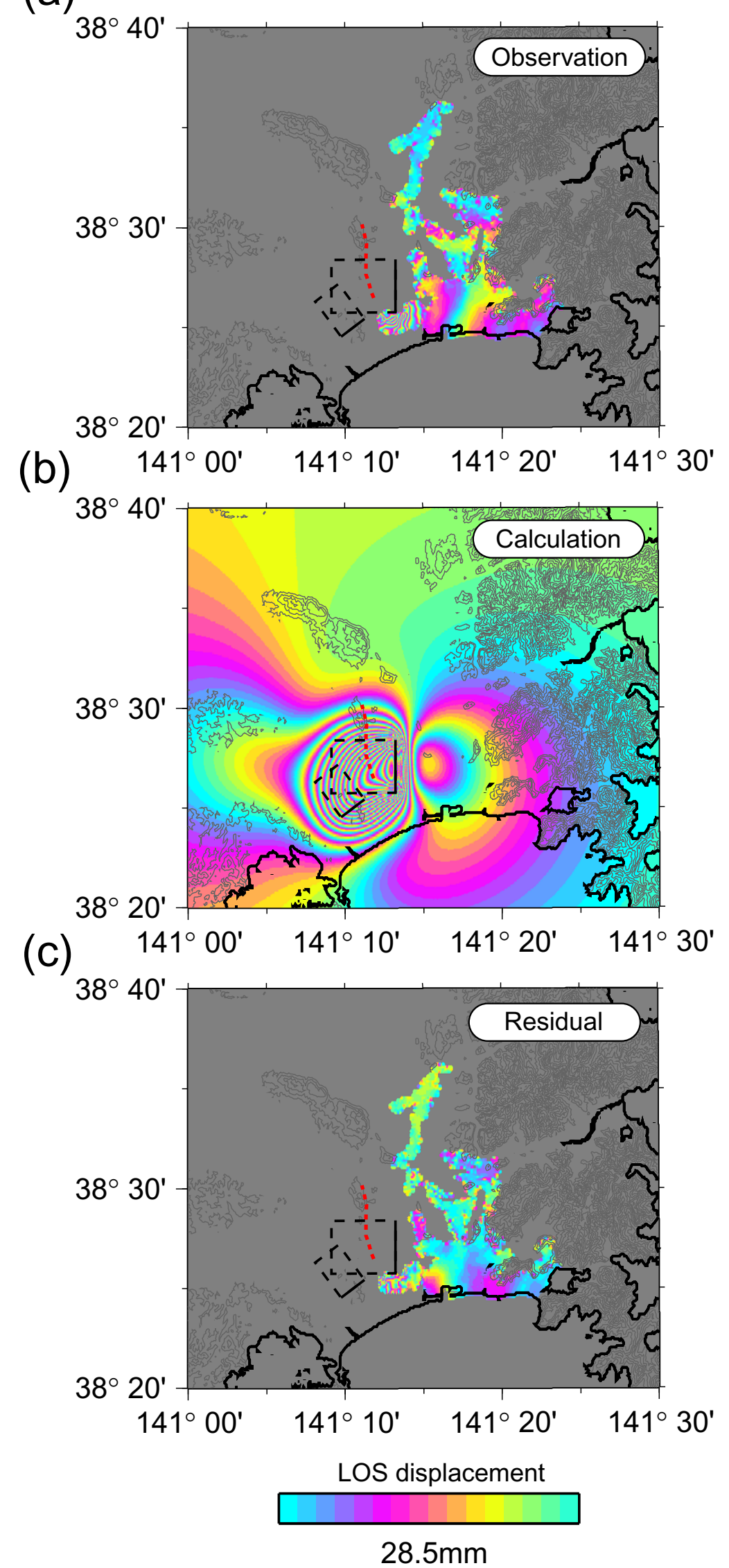

Fig. 5. Interferograms showing the deformation of the M6.4 northern Miyagi earthquake. SAR data were acquired on June 13 and July 31 by RADARSAT. Each color cycle represents $28.5 \mathrm{~mm}$ of change in the line of sight (LOS) to the satellite. (a) Observed interferogram. Gray area indicates bad coherence of two radar images. (b) Interferogram calculated by the model. (c) Residual interferogram (observation-calculation). 
Table 1. Information about the datasets.

\begin{tabular}{|c|c|c|c|c|c|}
\hline Data Type & Component & $\begin{array}{c}\text { Number of } \\
\text { data }\end{array}$ & $\begin{array}{c}\text { Uncertainties } \\
(\mathrm{mm})\end{array}$ & $\begin{array}{c}\text { Weight } \\
(\%)\end{array}$ & $\begin{array}{l}\text { RMS } \\
(\mathrm{mm})\end{array}$ \\
\hline \multirow[t]{2}{*}{ Continuous GPS } & Horizontal & 46 & $2.4^{*}$ & 22 & 7.3 \\
\hline & Vertical & 23 & 10 & 2.7 & 6.1 \\
\hline \multirow{2}{*}{$\begin{array}{l}\text { Campaign GPS at } \\
\text { permanent pillars }\end{array}$} & Horizontal & 12 & 10 & 1.4 & 6.7 \\
\hline & Vertical & 6 & 20 & 0.3 & 15 \\
\hline $\begin{array}{l}\text { Campaign GPS at } \\
\text { triangulation points }\end{array}$ & Horizontal & 22 & 20 & 1.4 & 23 \\
\hline Leveling & & 49 & $5.8^{*}$ & 9.8 & 6.7 \\
\hline InSAR & & 1601 & 30 & 62 & 8.0 \\
\hline Total & & 1759 & & 100 & \\
\hline
\end{tabular}

Table 2. Estimated fault parameters.

\begin{tabular}{|c|c|c|c|c|c|c|c|c|c|}
\hline & $\begin{array}{c}\text { Latitude* }^{*} \\
\left({ }^{\circ}\right)\end{array}$ & $\begin{array}{c}\text { Longitude* }^{*} \\
\left({ }^{\circ}\right)\end{array}$ & $\begin{array}{l}\text { Depth } \\
(\mathrm{km})\end{array}$ & $\begin{array}{c}\text { Length } \\
(\mathrm{km})\end{array}$ & $\begin{array}{l}\text { Width } \\
(\mathrm{km})\end{array}$ & $\begin{array}{c}\text { Strike } \\
\left({ }^{\circ}\right)\end{array}$ & $\begin{array}{l}\text { Dip } \\
\left({ }^{\circ}\right)\end{array}$ & $\begin{array}{c}\text { Rake } \\
\left({ }^{\circ}\right)\end{array}$ & $\begin{array}{l}\text { Slip } \\
\text { (m) }\end{array}$ \\
\hline Segment 1 & 38.479 & 141.219 & 0.7 & 5.3 & 7.9 & 181 & 38 & 108 & 0.95 \\
\hline Segment 2 & 38.425 & 141.187 & 3.4 & 3.1 & 6.3 & 234 & 40 & 93 & 1.32 \\
\hline
\end{tabular}

*The coordinate system is Japanese Geodetic Datum 2000 (JGD2000).

placements at triangulation points by campaign GPS are assumed 10, 20, and $20 \mathrm{~mm}$, respectively. InSAR data provides us the LOS displacement at more than 160000 points. However, it is ineffective for inversion to use all data points. We selected 1601 observation points by picking up one from every 100 points of the original data. We assumed $30 \mathrm{~mm}$ of uncertainties in the LOS displacement from one radar wavelength of $28.5 \mathrm{~mm}$.

The number of data, the assumed data uncertainties, and the data weight are listed in Table 1. Data weighting suggests that our inversion depends on InSAR data, horizontal displacements at continuous GPS stations, and vertical displacement by leveling. The other sub-datasets do not affect parameter estimation so much but can provide additional information.

\subsection{Inversion Procedure and Results}

We used the non-linear inversion method by Matsu'ura and Hasegawa (1987) to estimate parameters of rectangular faults. We assumed a homogeneous elastic half-space to calculate displacements due to rectangular faults (Okada, 1992). First, we tried to explain the observed data by a single rectangular fault. However, the single fault model could not fit all sub-datasets quantitatively. Though the leveling data suggest northeast-southwest strike of the reverse fault, horizontal GPS displacement beyond the epicentral area suggests the north-south strike of the fault. The model fitting the horizontal GPS data cannot explain the leveling data, and vice versa. We therefore need two rectangular faults to get reasonable fitting of all data. The setting of two segments is strongly supported not only by the residual reduction by half between the single and the two segment models, but also by aftershock distribution discussed later. In the non-linear inversion, the estimated parameter may be dependent on the initial parameters. In addition, the inversion method used in this study constrained the parameters to their initial value. However, we do not consider that the inversion result is much dependent on the initial parameters because our constraint is quite loose and there are no significant difference of the results starting from several sets of initial parameters. The estimated parameters are listed in Table 2. Assuming rigidity of $30 \mathrm{GPa}$, seismic moments of Segments 1 and 2 respectively are $1.1 \times 10^{18} \mathrm{~N} \cdot \mathrm{m}$ and $0.6 \times 10^{18} \mathrm{~N} \cdot \mathrm{m}$, totaling up to $1.8 \times 10^{18} \mathrm{~N} \cdot \mathrm{m}\left(\mathrm{M}_{w} 6.1\right)$. Comparison between the observation and the model calculation is shown in Figs. 2, 3, 4 , and 5 . The root-mean square (RMS) of the residuals for each sub-dataset is listed in Table 1. The model explains the observed data well except the horizontal displacements at triangulation points. Disagreement of the data at the triangulation points should be attributed to large measurement errors rather than the problem of modeling. In the near field of the fault, significant misfits between the observation and calculation are found in GPS (Figs. 2 and 3), leveling (Fig. 4), and InSAR data (Fig. 5). These suggest a limitation of the uniform slip on the segments and complex geometry of the fault. Dip angle of the fault may be variable particularity in shallow sediment (e.g. Nishimura et al., 2001). The residual plot of InSAR data (Fig. 5(c)) shows spatially coherent misfit around $38^{\circ} 25^{\prime} \mathrm{N}$ and $141^{\circ} 16^{\prime} \mathrm{E}$. In this area, leveling data also show subsidence predicted by the model is smaller than the observed one around J2. It may suggest a fault slip in the southern extension of Segment 1. Variable slip distribution on the fault segments is necessary to explain the observed displacement close to the fault.

\section{Discussion}

The most interesting feature of the estimated fault model is that the model consists of two rectangular fault segments whose strike differs by $50^{\circ}$ (Figs. 2 and 3). Because the difference of rake between two segments is only $15^{\circ}$, slip vectors on two segments are significantly different in direction, as shown in Fig. 3. The different slip vectors may reflect heterogeneity of stress field in the hypocentral region. Precise aftershock distribution with temporary seismic station in the epicentral area (Okada et al., 2003) shows strike of planes 
formed by aftershocks also differ in the southern and northern parts of the aftershock region. The hypocenter of the main-shock locates in the southern part of the aftershock region. The focal mechanisms estimated from initial phases of P-wave and by waveform inversion are also differs considerably (Okada et al., 2003). The fault orientations of Segments 1 and 2 are similar to the focal mechanisms from waveform inversion and initial phases, respectively. These suggest the rupture initiated on Segment 2 and propagated to Segment 1 releasing large seismic moment there.

Strike of Segment 1 is $181^{\circ}$ and approximates to that of the Asahiyama flexure which might be considered as a source fault of the main-shock. However, an extension of Segment 1 to the surface locates $\sim 3 \mathrm{~km}$ east of the surface trace of the Asahiyama flexure. Sharp gradient of the vertical displacement calculated by the fault model also locates near the surface extension of Segment 1. The large offset between 960549 and J2 measured by leveling (Fig. 4) locates east of the southern extension of the Asahiyama flexure. Therefore, the M6.4 northern Miyagi earthquake did not rupture the fault formed the Asahiyama flexure and its recurrence can make a geomorphologic flexure not at the Asahiyama flexure but $\sim 3 \mathrm{~km}$ east of the Asahiyama flexure. On the other hand, there are no Quaternary active faults around Segment 2. We point out that strike of Segment 2 is close to the NagamachiRifu fault, and that Segment 2 locates in the extension of the Nagamachi-Rifu fault (Figs. 1 and 2). There may be a tectonic joint of north-south strike active faults such as the Asahiyama flexure and northeast-southwest strike ones extending to the southwest such as the Nagamachi-Rifu fault.

Nishimura et al. (2004a) studied crustal deformation observed by the continuous GPS in Miyagi Prefecture including the epicentral area. Though high strain rate localized in west of the Nagamachi-Rifu fault which is $30 \mathrm{~km}$ southwest of the epicentral region, strain rate in the epicentral area shows compression of $\sim 2 \times 10^{-7} / \mathrm{yr}$ in the ESE-WNW direction which is spatially homogeneous in and around the epicentral region. Any significant deformation before the earthquake are not detected in the daily coordinate of the continuous GPS. Leveling data do not show any significant vertical displacement for a year just before the earthquake in the epicentral area, neither. We conclude that there is no pre-seismic signal larger than a few millimeters measured by leveling and GPS.

There are a few apparent discrepancies between the hypocentral distribution and the location of the estimated fault model. First, the map view of the estimated fault location and the epicenter of the main-shock (Fig. 3) shows that the epicenter locates beyond the fault. We think this discrepancy suggests small fault slip at the hypocenter. Second discrepancy is the difference of depth. Though the depth of aftershocks ranges from 3 to $12 \mathrm{~km}$ (Okada et al., 2003), that of the fault model ranges 1 to $7 \mathrm{~km}$. It suggests that the main-shock ruptured in the shallow part of the fault and aftershocks are active in the deeper extension of the main-shock fault. In addition, we attribute a soft sedimentary layer near the surface in the region to a modeling error of the geodetic inversion. Savage (1998) pointed out that a low-elastic modulus layer causes the half-space equivalent dislocation to appear shallower than the actual dislocation in the layered half space. Modeling including variable slip on the faults and an elastic layered medium should be considered in the next step of our work.

\section{Conclusions}

We analyzed geodetic data associated with the M6.4 northern Miyagi earthquake. Exceptional large amount of geodetic data observed by InSAR, continuous and campaign GPS, and leveling suggests that two reverse-type fault segments whose strikes are $\sim 180^{\circ}$ and $\sim 230^{\circ}$, respectively. The significant direction difference of slip vectors for two segments suggests heterogeneity of stress field in the hypocentral region.

Acknowledgments. We thank members of Research Planning Div., Mobile Observation Div., Second Geodetic Div., and Satellite Geodesy Div. of the Geographical Survey Institute for providing the geodetic data and telling us the information in the epicentral area. We are grateful to Jim Savage and Teruyuki Kato for useful reviews and suggestions. The hypocentral data were provided by the Japan Meteorological Agency in cooperation with the Ministry of Education, Culture, Sports, Science, and Technology. The RADARSAT data were received by the Canada Centre for Remote Sensing.

\section{References}

Active Fault Research Group, Active Faults in Japan: sheet maps and inventories (Revised edition), 437 pp., University of Tokyo Press, Tokyo, 1991 (in Japanese).

Goldstein, R. M. and C. L. Werner, Radar interferogram filtering for geophysical applications, Geophys. Res. Let., 25, 4035-4038, 1998.

Massonnet, D., K. L. Rossi, C. Carmona, F. Adragna, G. Peltzer, K. Fiegl, and T. Rabaute, The displacement field of the Landers earthquake mapped by radar interferometry, Nature, 364, 138-142, 1993.

Matsu'ura, M. and Y. Hasegawa, A maximum likelihood approach to nonlinear inversion under constraints, Phys. Earth Planet. Inter., 47, 179187, 1987.

Nishimura, T., S. Fujiwara, M. Murakami, M. Tobita, H. Nakagawa, T. Sagiya, and T. Tada, The M6.1 earthquake triggered by volcanic inflation of Iwate volcano, northern Japan, observed by satellite radar interferometry, Geophys. Res. Let., 28, 635-638, 2001.

Nishimura, T., T. Sagiya, and S. Miura, Crustal deformation around the Nagamachi-Rifu fault zone and its vicinity (central Tohoku), northeastern Japan, observed by continuous GPS measurements, Zisin, 2004a (in press) (in Japanese with English abstract).

Nishimura, T., T. Hirasawa, S. Miyazaki, T. Sagiya, T. Tada, S. Miura, and K. Tanaka, Temporal change of interplate coupling in northeastern Japan during 1995-2002 estimated from continuous GPS observations, Geophys. J. Int., 2004b (in press).

Okada, Y., Internal deformation due to shear and tensile faults in a halfspace, Bull. Seismol. Soc. Am., 82, 1018-1040, 1992.

Okada, T., N. Umino, and A. Hasegawa, Rupture process of the July 2003 northern Miyagi earthquake sequence, NE Japan, estimated from doubledifference hypocenter locations, Earth Planets Space, 55, this issue, 741$750,2003$.

Sagiya, T., Crustal movements as earthquake precursors-Leveling anomaly before the 1944 Tonankai Earthquake revisited-, Bull. Geogra. Surv. Inst., 44, 23-36, 1998.

Sagiya, T., S. Miyazaki, and T. Tada, Continuous GPS array and present-day crustal deformation of Japan, PAGEOPH, 157, 2303-2322, 2000.

Sato, H., Some precursors prior to recent great earthquakes along the Nankai Trough, J. Phys. Earth, 25, S115-S121, 1977.

Savage, J. C., Displacement field for an edge dislocation in a layered halfspace, J. Geophys. Res., 103, 2439-2446, 1998.

Yarai, H., T. Ozawa, T. Nishimura, and T. Imakiire, Crustal deformation associated with the northern Miyagi earthquake detected by RADARSAT and ENVISAT SAR interferometry, Earth Planets Space, 2003 (submitted).

T. Nishimura (e-mail: t_nisimura@gsi.go.jp), T. Imakiire, H. Yarai, T. Ozawa, M. Murakami, and M. Kaidzu 